\title{
Difficulties in emotion regulation, separation anxiety, and impulsivity as predictors of women's intimate partner violence experiences
}

\author{
Yasemin Kayha ${ }^{1 \oplus}$, Nermin Taskale $^{2 \oplus}$ \\ 'Social Sciences University of Ankara, Faculty of Humanities and Social Sciences, Department of Psychology, Ankara - Turkey \\ ${ }^{2}$ Istanbul University Faculty of Letters, Department of Psychology, Istanbul - Turkey
}

\begin{abstract}
Objective: The first purpose of the current study was to examine the typology of intimate partner violence experiences of community sample women via two-step cluster analysis. The second purpose was to investigate how difficulties in emotion regulation, separation anxiety, and impulsivity would predict the clusters of intimate partner violence including both victim and perpetrator roles.

Method: A total of 253 female participants who were married/in a relationship currently or during the past year were included in the statistical analyses. Participants completed online a Demographic Information Form, the Revised Conflict Tactics Scale-2, the Difficulties in Emotion Regulation Scale, the Adult Separation Anxiety Questionnaire, and the Short Form of the Barratt Impulsiveness Scale.

Results: The two-step clustering method indicated that violence experiences of women in the community who were mostly victims of psychological violence fell into two different clusters of low and moderate violence experiences. The total scores of difficulties in emotion regulation and separation anxiety symptoms increased the likelihood of being in the moderate violence cluster while the total score of impulsivity was not related to violence clusters.

Conclusion: Violence experience of women in the community is a complex phenomenon that simultaneously includes victim and perpetrator roles and is experienced at different levels. Findings underlined the role of women's affect-regulation difficulties and their feelings towards significant others and intimate relationships in their violence experiences.
\end{abstract}

Keywords: Affect, impulsive behavior, intimate partner violence, separation anxiety

\section{INTRODUCTION}

Intimate partner violence encompasses the physical, sexual, and/or psychological violence that a female or male partner initiates towards their significant other (1). Recent studies in the international literature conducted in community samples emphasize the bidirectional nature of intimate partner violence between women and men (2), while studies in Turkey mostly focus on women's role as victims $(3,4)$. However, studies in community samples have shown that women and men can equally be victim or perpetrator in an intimate relationship (5). At the same time, for women being in the role of perpetrator is a further risk factor for being

How to cite this article: Kayha Y, Taskale N. Difficulties in emotion regulation, separation anxiety, and impulsivity as predictors of women's intimate partner violence experiences. Dusunen Adam The Journal of Psychiatry and Neurological Sciences 2019;32:101-12.

Correspondence: Yasemin Kahya, Social Sciences University of Ankara, Faculty of Humanities and Social Sciences, Department of Psychology, Hukumet Meydani, No. 2, 06030 Ulus, Altindag, Ankara - Turkey

Phone: +90 3125964444 E-mail: yaseminoruclular@gmail.com

Received: November 21, 2018; Revised: December 11, 2018; Accepted: March 11, 2019 
revictimized (6). On the other hand, women can be exposed to various kinds of violence simultaneously so that we need to assess violence beyond two simple categories of "being present" and "being absent" (7). To be able to understand violence better, we need to consider its dimensions to the point of addressing the roles of perpetrator and victim jointly. Examining the differences in the occurrence of violence may be possible if we are better able to characterize the participants that can be divided into different groups. Studies in the national and international literature with different samples from the community, forensic institutions, and women shelters also indicate that women experiencing violence do not constitute a homogeneous group but include various subgroups $(8,9)$.

Recent studies on intimate partner violence have examined the potential role of difficulties in emotion regulation, a proximal risk factor open to intervention. One study reported that women who perpetrated physical and psychological violence were distinguished from those who did not by difficulties in emotion regulation (10). It was also seen that in cases where women perpetrated violence, unless they did so in selfdefense, these events were related with the inability to regulate their expression of anger (11). Difficulties in emotion regulation also played a role in women suffering from repeated sexual violence (6). According to the findings, emotional instability increases the probability for women to engage in risky behavior, thus causing a tendency to become victims (12). A study using latent class analysis found that women who experienced various levels of violence reported greater difficulties in regulating emotions compared to women who did not have any violence experience (13). Therefore, even though women's experience of intimate partner violence is dysfunctional, it may have had an emotion-regulating function (14).

According to Berzenski and Yates (15), having problems with impulsive behavior control, which is a subcomponent of difficulties in emotion regulation (16), remains limited to encompassing the behavioral dimension of impulsivity. It is therefore necessary to understand to what degree impulsivity, in addition to difficulties in emotion regulation, has a part in women's intimate partner violence experiences. While there are only few studies examining the relation between women perpetrating violence in intimate relationships and impulsive characteristics, this area has attracted more attention recently (17). Empirical findings also confirmed that impulsivity may be a predictive factor for female participants perpetrating violence $(17,18)$. A study with couples found that difficulties in tolerating the partner's negative emotions were related with participants being victims of physical violence, indicating that impulsivity might have an impact on becoming a victim of violence (19).

Another variable that may affect intimate partner violence is separation anxiety experienced in adulthood. Compared to men, women are more likely to report signs of adult separation anxiety (20). Being a disorder defined with DSM-5, it has not yet been commonly researched empirically in violence studies (21). For example, a study with males found that men who perpetrated violence against their spouses experienced more separation anxiety (22). We could only find one empirical study examining separation anxiety and intimate partner violence in a female sample, reporting that in women with core separation anxiety symptoms, intimate partner violence was chronic and the rate of suffering physical violence was quite high (23). Theorists of attachment have pointed out that the closeness and distance preferences of individuals with separation anxiety in a relationship may differ; thus violence may be used to regulate the "socioemotional distance" with the partner (24).

The first aim of this study is to generate a typology of violence experiences in female participants who are currently or were during the past year married or in an intimate relationship. Therefore, considering women's victim and perpetrator roles together in the dimensions of physical, psychological, and sexual violence and injury, we aimed to cluster violence experiences with common patterns. In accordance with this aim, it is hypothesized that violence can be simultaneously suffered and perpetrated in more than one dimension and the dimensions of violence can be dominant to different degrees in the distribution between clusters $(5,6,8,9)$. Thus, by analyzing the complex nature of violence beyond categorical approaches "victim of violence" versus "perpetrator of violence," it will be possible to show the existence of violence clusters that significantly differ between one another. The second aim of the study is to examine to what degree difficulties in emotion regulation, impulsivity, and separation anxiety differentiate the violence clusters established considering women's victim and perpetrator roles together. In that sense, according to the second hypothesis of this study, it is expected that the most severe group in the violence clusters experiences more difficulties in emotion regulation, impulsivity, and separation anxiety $(14,17,19,23)$. In the context of the second aim, these relations will be examined through exploratory analyses in the framework of the 
subdimensions of the variables, difficulties in emotion regulation and impulsivity. Intervention programs focusing exclusively on male perpetrators may be of limited explanatory value regarding intimate partner violence and have a low impact (25). We therefore assert that our study, examining violence clusters determined by looking at women's roles both as perpetrators and victims in the context of difficulties in emotion regulation, impulsivity, and adult separation anxiety, will be a conceptual contribution to intervention programs against violence.

\section{METHOD}

This study aimed to reach women of age 18 and above who were currently married or in a romantic relationship or had been so in the past year. Within this scope, at the data collection stage 307 individuals participated via online data collection channels. The basic inclusion criteria were being female and currently having an intimate partner or having had one during the previous year. Twelve participants not meeting the inclusion criteria and 42 outliers were excluded from the sample; the size of the sample included in the analyses was 253 . Mean age of the sample was 26.48 years $(\mathrm{SD}=6.58)$. Of the participants, $28.9 \%$ were married, while $86.6 \%$ of the single participants were currently in a romantic relationship. Participants not currently married or in a romantic relationship affirmed that they had been in a relationship during the last year. Of the participants, 92.9\% were graduates from a university or had a higher degree. The perceived socio-economic level was predominantly "moderate" (79.4\%). The participants' demographic characteristics are summarized in Table 1.

\section{Measures}

Demographic Information Form (DIF): Prepared by the research team, the DIF aimed to collect data related to variables such as age, sex, marital status, level of education, employment status, and perceived socioeconomic status. The question if participants were married or in a romantic relationship during the study period or had been in the last year was assessed in the context of the DIF.

Revised Conflict Tactics Scale-2 (CTS2): Developed by Straus et al. (26), the CTS2 measures the degree to which couples that are courting, living together, or are in a marital relationship show physical, sexual and/or psychological violence. The instrument consists of 78 items. Participants mark on a Likert-type scale how often they experienced violence behavior as specified in the
Table 1: Findings regarding participants' demographic characteristics and experience of violence

\begin{tabular}{lcc} 
Variable & Mean & SD \\
\hline Age & 26.48 & 6.58 \\
Variable & $\mathbf{n}$ & $\%$ \\
\hline
\end{tabular}

\section{Level of education}

$\begin{array}{lcc}\text { Primary } & 1 & 0.4 \\ \text { Middle school } & 1 & 0.4 \\ \text { High school } & 10 & 4.0 \\ \text { Vocational school } & 6 & 2.4 \\ \text { University } & 140 & 55.6 \\ \text { Postgraduate } & 94 & 37.3 \\ \text { come level } & & \\ \text { Low } & 34 & 13.4 \\ \text { Moderate } & 201 & 79.4 \\ \text { High } & 18 & 7.1 \\ \text { Marital status } & & \\ \text { Single } & 180 & 71.1 \\ \text { Married } & 73 & 28.9\end{array}$

\section{(For participants being} single:) currently in a

romantic relationship

$\begin{array}{lcc}\text { Yes } & 155 & 86.6 \\ \text { No } & 24 & 13.4\end{array}$

Victim of violence

$\begin{array}{lcc}\text { Psychological } & 209 & 89.3 \\ \text { Physical } & 27 & 10.7 \\ \text { Sexual } & 71 & 28.1 \\ \text { Injuries } & 4 & 1.6\end{array}$

Perpetrator of violence

$\begin{array}{lcc}\text { Psychological } & 217 & 85.8 \\ \text { Physical } & 53 & 20.9 \\ \text { Sexual } & 57 & 22.5 \\ \text { Injury } & 9 & 3.6\end{array}$

items of the scale during the last year and how often they had directed these behaviors towards their partner. A validity and reliability study for the Turkish version of the CTS2 by Aba and Kulakac (27) found the scale to be a valid and reliable instrument. In this study, the internal consistency coefficient was 0.86 .

Difficulties in Emotion Regulation Scale (DERS): This instrument, developed by Gratz and Roemer (16), consists of 36 items being evaluated on a 5-point Likerttype scale. Ruganci and Gencoz (28) carried out a validity and reliability study for the Turkish adaptation, finding the Turkish DERS to be valid and reliable. The Turkish adaptation study showed that the scale 
consisted of the subdimensions Limited Access to Emotion Regulation Strategies (STRATEGIES), NonAcceptance of Emotional Responses (NONACCEPTANCE), Impulse Control Difficulties (IMPULSE), Lack of Emotional Clarity (CLARITY), Lack of Emotional Awareness (AWARENESS), and Difficulties Engaging in Goal-Directed Behavior (GOALS). Cronbach's alpha validity coefficient for the entire scale was 0.95 in this study.

Short Form of the Barratt Impulsiveness Scale (BIS-11-SF): The latest version, BIS-11, was developed by Patton et al. (29) and adapted to Turkish by Gulec et al. (30). For ease of use, Tamam et al. (31) developed a shortened Turkish 15-item version on the basis of the original 30 -item BIS-11, which they called BIS-11-SF (independently from a short version used in different languages under the name BIS-15), and demonstrated its validity and reliability. This form consisted of the dimensions Non-Planning Impulsiveness (BSI-11-SFNPI), Motor Impulsiveness (BSI-11-SF-MI), and Attentional Impulsiveness (BSI-11-SF-AI). The study showed BIS-11-SF to be a valid and reliable scale. In this study, Cronbach's alpha internal consistency coefficient was 0.83 .

Adult Separation Anxiety Questionnaire (ASA27): Developed by Manicavasagar et al. (32) to measure separation anxiety in the adult age, the ASA-27 consists of 27 items that the participants rate on a 4-point Likert-type scale. A validity and reliability study for the Turkish version of the ASA-27 was conducted by Dirioz et al. (33) showing the Turkish adaptation to be a valid and reliable single-factor measuring instrument. In this study, Cronbach's alpha internal consistency coefficient was 0.92 .

\section{Procedure}

Before beginning the study, the required approval from the ethics committee of Hacettepe University was received. Women fitting the inclusion criteria for the study were reached via social communication networks. Study data were collected through the site www.surveey. com between March and May 2017. As data were collected online, the first page of the instrument set consisted of the informed consent form. After giving consent, participants answered the questions in the instrument set. Completing the instrument set took around 30-40 minutes for each participant.

\section{Statistical Analysis}

For data analysis, SPSS version 21 was used (34). Before analyzing the data, variables were checked for distribution, finding that they contained a large number of outliers and were not normally distributed, which is consistent with the literature on intimate partner violence $(35,36)$. Subsequently, data from 42 participants falling into the top $1 \%$ of the data set (being outliers with a $\mathrm{z}$ value above 3.29 ) and violating the assumptions of regression analysis were removed (37). In order to be able to assess the regressive correlations in the remaining participants' not normally distributed data, logarithmic transformation was applied (37). Potential clusters in the data set were assessed with twostage cluster sampling. In this method, in the first step each case is assumed to be a cluster (38). These clusters, whose number equals the number of cases, are merged on the basis of similarities between them. This merging procedure ends when the desired number of clusters is reached. The inter-cluster distance is the main criterion and derived from probabilistic models. In this process, a hierarchical agglomerative clustering algorithm with log-likelihood distance is used. In the end, intra-cluster distances represent similarities among cases and intercluster distances represent differences between cases. Thus, two-stage cluster sampling is a method to detect clusters already existing in a data set based upon their continuous or categorical variables. The aim is to reveal the latent cluster structure in the data set without determining the number of clusters in advance of the detection process. In this study, the cluster structure is assessed using the continuous variables for being a victim of violence and perpetrating violence as a basis. Variables predicting the resulting clusters are assessed with binary logistic regression analysis (37).

\section{RESULTS}

Before starting analyses addressing the research question, we assessed the participants' violence experiences. According to the percentages obtained using CTS2, $82.6 \%$ of the women reported having suffered at least one instance of psychological violence, $10.7 \%$ at least one case of physical, and $28.1 \%$ at least one occurrence of sexual violence; $1.6 \%$ had at least once been injured. On the other hand, the CTS2 percentages for the perpetration of intimate partner violence, women indicated that they had at least once perpetrated psychological, physical, or sexual violence or caused injury to their partner were 85.8, 20.9, 22.5, and $3.6 \%$, respectively (see Table 1 ). The following scores were reported for the dimensions of violence experiences: mean score for perpetrating psychological violence $10.20(\mathrm{SD}=11.50)$, mean score for suffering 
psychological violence $7.32(\mathrm{SD}=8.61)$, mean score for perpetrating physical violence $1.01(\mathrm{SD}=3.56)$, mean score for suffering physical violence $0.41(\mathrm{SD}=1.71)$, mean score for perpetrating sexual violence 1.14 $(\mathrm{SD}=3.34)$, mean score for suffering sexual violence $2.07(\mathrm{SD}=5.28)$, mean score for causing injury 0.08 $(\mathrm{SD}=0.55)$, mean score for suffering violence 0.04 $(\mathrm{SD}=0.41)$, mean total score for perpetrating violence 12.44 ( $\mathrm{SD}=13.07)$, and mean total score for suffering violence $9.84(\mathrm{SD}=11.36)$.

In order to assess if the participants constituted a single group with regard to the CTS2 scores for perpetrating and suffering physical, sexual, and psychological violence and injuries, two-stage cluster analysis was performed, showing that the participants were patterned between 4 different clusters. We named the first cluster of participants who scored the lowest scores for all types of violence "group with low violence experience." The second cluster with higher scores of psychological violence victimization and perpetration compared to the other clusters was called "group characterized by psychological violence experience." A third cluster in which sexual violence victimization and perpetration scores were higher than in the other clusters was called "group characterized by sexual violence experience." Finally, the cluster with higher scores of physical violence victimization and perpetration was called "group characterized by physical violence experience." The order of the most important predictors for constituting the clusters was suffering sexual violence, perpetrating psychological violence, perpetrating physical violence, perpetrating sexual violence, suffering psychological violence, causing injury, suffering physical violence, and suffering injury. The number of participants (percentage) was as follows: 163 (64.4\%), 60 (23.7\%), 20 (7.9\%), and 10 $(4.0 \%)$, respectively. The uneven distribution of the participants among the clusters suggested that the data might not be suitable for regressive analyses; therefore, the cluster analysis was repeated using the total CTS2 scores for intimate partner violence victimization and perpetration. Thus, in the constitution of the clusters in the data set and the following analyses, total scores for victimization and perpetration of all violence dimensions have been used.

The new cluster structure showed that participants were divided into two clusters. The first cluster, consisting of relatively lower scores for victimization and perpetration, was called "group with low violence experience," while the second cluster with relatively higher scores for victimization and perpetration was called, considering the scores, "group with moderate violence experience." In constituting the clusters, scores or violence victimization and perpetration were rredictive at a similar level. The number (percentage) of participants in each cluster was 173 (68.4\%) and 80 (31.6\%), respectively.

At the last step, binary logistic regression analysis was performed with the categorical variables for the "group with low violence experience" and the "group with moderate violence experience" as dependent variable and the total DERS, BIS-11-SF, and ASA-27 scores together as predictor variables. In the absence of predictive variables, the correct cluster prediction proportion in the dependent variable was $68.4 \%$ and the constant value was significant $(B=-0.77, S H=0.14$, $\mathrm{p}<0.001)$. When the total DERS, BIS-11-SFi and ASA27 score were added to the model, the proportion of correct predictions increased to $71.5 \%\left(\chi^{2}(3)=15.94\right.$, $p=0.001$, Nagelkerke $R^{2}=0.09$ ). With an increase in the total DERS score, the probability of experiencing a moderate rather than a low level of violence increased 5 times $(\mathrm{B}=1.70, \mathrm{SH}=0.62, \mathrm{p}<0.01)$. ASA $-27(\mathrm{~B}=0.29$, $\mathrm{SH}=0.33, \mathrm{p}=0.37)$, and BIS-11-SF $(\mathrm{B}=-0.15, \mathrm{SH}=0.77$, $\mathrm{p}=0.85$ ) total scores had been found correlated with the violence experience clusters. The constant value of the model was significant $(\mathrm{B}=-8.68, \mathrm{SH}=2.78, \mathrm{p}<0.01)$ (Table 2).

An analysis carried out using the total scores of the predictive variables together was repeated in order to understand better the contribution of the scales' subdimensions to the model, using the DERS subdimensions (strategies, non-acceptance, impulse, clarity, awareness, and goals), the BIS-11-SF subdimensions (BSI-11-SF-NPI, BSI-11-SF-MI, and BSI-11-SF-AI), and the total score of ASA-27, which is one-dimensional. In the absence of predictive variables, the correct cluster prediction proportion in the dependent variable was $68.4 \%$ and the constant value was significant $(\mathrm{B}=-0.77, \mathrm{SH}=0.14, \mathrm{p}<0.001)$. After adding the DERS and BIS-11-SF subdimensions and the total ASA-27 score to the model, the proportion of correct predictions rose to $73.1 \%\left(\chi^{2}(10)=31.05\right.$, $\mathrm{p}=0.001$, Nagelkerke $\left.\mathrm{R}^{2}=0.16\right)$. It was seen that with an increase in the strategies score by one unit, the probability to experience moderate rather than lowlevel violence decreased marginally by $77 \%(B=-1.47$, $\mathrm{SH}=0.62, \mathrm{p}=0.06$ ), while with an increase in the IMPULSE score by one unit, it increased 8 -fold $(B=2.08$, $\mathrm{SH}=0.71, \mathrm{p}<0.01$ ), and with an increase by one unit in the BSI-11-SF-MI score, it decreased with marginal significance by $80 \%(B=-1.59, \mathrm{SH}=0.80, \mathrm{p}=0.047)$. The 
Table 2: Findings regarding the predictive role of DERS, BIS-11-SF, and ASA-27 total and dimension scores as predictors of the low- vs. moderate-level violence experience cluster

\begin{tabular}{|c|c|c|c|c|}
\hline Variables & B & Standard error & $\mathbf{p}$ & Risk ratio \\
\hline \multicolumn{5}{|c|}{$\begin{array}{l}\text { Model with total DERS, BIS-11-SF, and ASA-27 scores } \\
\text { as predictors }\end{array}$} \\
\hline DERS & 1.70 & 0.62 & 0.006 & 5.48 \\
\hline BIS-11-SF & -0.15 & 0.77 & 0.850 & 0.87 \\
\hline ASA-27 & 0.29 & 0.33 & 0.370 & 1.34 \\
\hline Constant & -8.68 & 2.78 & 0.002 & $<0.001$ \\
\hline \multicolumn{5}{|c|}{$\begin{array}{l}\text { Model with DERS dimensions, BIS-11-SF dimensions, } \\
\text { and ASA-27 total scores as predictors }\end{array}$} \\
\hline Strategies dimension & -1.47 & 0.79 & 0.06 & 0.23 \\
\hline Non-Acceptance dimension & 0.91 & 0.56 & 0.105 & 2.48 \\
\hline Impulse dimension & 2.08 & 0.71 & 0.003 & 8.04 \\
\hline Clarity dimension & 0.14 & 0.70 & 0.847 & 1.14 \\
\hline Awareness dimension & -0.59 & 0.65 & 0.365 & 0.55 \\
\hline Goals dimension & 0.42 & 0.69 & 0.550 & 1.51 \\
\hline BSI-11-SF-NPI dimension & 0.94 & 0.81 & 0.249 & 2.55 \\
\hline BSI-11-SF-MI dimension & -1.59 & 0.80 & 0.047 & 0.20 \\
\hline BSI-11-SF-AI dimension & 0.15 & 1.00 & 0.878 & 1.17 \\
\hline ASA-27 & 0.47 & 0.35 & 0.181 & 1.60 \\
\hline Constant & -4.59 & 2.20 & 0.037 & 0.01 \\
\hline \multicolumn{5}{|c|}{ Model with total DERS score as predictor } \\
\hline DERS & 1.92 & 0.51 & $<0.001$ & 6.84 \\
\hline Constant & -9.17 & 2.26 & $<0.001$ & $<0.001$ \\
\hline \multicolumn{5}{|c|}{ Model with total BIS-11-SF score as predictor } \\
\hline BIS-11-SF & 0.99 & 0.69 & 0.15 & 2.70 \\
\hline Constant & -4.09 & 2.30 & 0.08 & 0.02 \\
\hline \multicolumn{5}{|c|}{ Model with total ASA-27 score as predictor } \\
\hline ASA-27 & 0.76 & 0.28 & 0.007 & 2.13 \\
\hline Constant & -3.27 & 0.95 & 0.001 & 0.04 \\
\hline
\end{tabular}

DERS: Difficulties in Emotion Regulation Scale total score, Strategies: DERS strategy score, Non-Acceptance: DERS acceptance score, Impulse: DERS impulsiveness, Clarity: DERS clarity score, Awareness: DERS awareness score, Goals: DERS goals score, BIS-11-SF: Short Form of the Barratt Impulsiveness Scale total score, BSI-11-SF-NPI: BIS-11-SF non-planning score, BSI-11-SF-MI: BIS-11-SF motor impulsiveness score, BSI-11-SF-AI: BIS-11-SF attentional impulsiveness score, ASA-27: Adult Separation Anxiety Questionnaire total score, $B=$ nonstandardized coefficient.

other subdimension scores were not found to be significantly predictive for the probability of experiencing moderate rather than low-level violence. The constant value of the model was significant $(\mathrm{B}=-$ $4.59, \mathrm{SH}=2.19, \mathrm{p}=0.04)$.

Multivariate analysis using the total scores of the predictive variables repeated with single-variate analyses aimed at detecting potentially hidden effects. For the analysis carried out for this purpose, binary logistic regression analysis was performed, and the total DERS score was used as predictive variable, and "low" and "moderate violence experience" groups as dependent variable. In the absence of the predictive variable, the proportion of correct cluster predictions in the dependent variable was $68.4 \%$ and the constant value was significant $(\mathrm{B}=-0.77, \mathrm{SH}=0.14, \mathrm{p}<0.001)$. After adding the total DERS score to the model, the proportion of correct predictions increased to $70.8 \%$ $\left(\chi^{2}(1)=15.10, p<0.001\right.$, Nagelkerke $\left.R^{2}=0.08\right)$. With an increase in the DERS total score by one unit, the probability to experience "moderate" rather than "lowlevel violence" increased 6 times $(B=1.92, S H=0.51$, $\mathrm{p}<0.001)$. The constant value of the model was significant $(\mathrm{B}=-9.17, \mathrm{SH}=2.26, \mathrm{p}<0.001)$.

In the second analysis, a binary logistic regression analysis was carried out with the total BIS-11-SF score 
as predictive and "low" or "moderate violence experience" groups as dependent variable. In the absence of the predictive variable, the proportion of correct cluster predictions in the dependent variable was $68.4 \%$ and the constant value was significant $(B=-$ $0.77, \mathrm{SH}=0.14, \mathrm{p}<0.001)$. After adding the total BIS-11SF score to the model, the proportion of correct predictions remained the same $\left(\chi^{2}(1)=2.13, \mathrm{p}=0.15\right)$. The probability of experiencing "moderate" rather than "low-level violence" was not significantly affected by a change in the total BIS-11-SF score $(\mathrm{B}=0.99, \mathrm{SH}=0.69$, $\mathrm{p}=0.15)$. The constant value of the model was marginally significant $(\mathrm{B}=-4.09, \mathrm{SH}=2.30, \mathrm{p}=0.08)$.

In the third analysis, binary logistic regression analysis was performed using the total ASA-27 score as predictive and the "low" and "moderate violence experience" groups as dependent value. In the absence of the predictive variable, the proportion of correct cluster predictions in the dependent variable was $68.4 \%$ and the constant value was significant $(B=-0.77$, $\mathrm{SH}=0.14, \mathrm{p}<0.001)$. After adding the total ASA-27 score to the model, the proportion of correct predictions remained the same $\left(\chi^{2}(1)=7.62, p<0.01\right.$, Nagelkerke $\left.\mathrm{R}^{2}=0.04\right)$. With an increase in the total ASA-27 score by one unit, the probability of experiencing "moderate" rather than "low-level violence" increased twofold $(\mathrm{B}=0.76, \mathrm{SH}=0.28, \mathrm{p}<0.01)$. The constant value of the model was significant $(\mathrm{B}=-3.27, \mathrm{SH}=0.95, \mathrm{p}=0.001)$.

\section{DISCUSSION}

The rates of violence experiences reported by our sample match those declared by similar groups from different cultures $(39,40)$. Looking at the participants from the perspective of violence subdimension scores suffering and perpetrating, we have seen that the sample can be grouped in 4 clusters, namely, group with low violence experience, group characterized by psychological violence experience, group characterized by sexual violence experience, and group characterized by physical violence experience. Looking at the violence scores of being victim and being perpetrator as total scores, the sample falls into 2 clusters, namely, groups experiencing violence at a low and a moderate level, respectively. These findings confirm the first hypothesis of the study that violence experience is a complex phenomenon that is experienced in different patterns and can be divided into different clusters. As far as we know, there is no other study in the literature analyzing the cluster structure of women's violence experience looking at victim and perpetrator scores simultaneously.
Thus the findings point not only to female participants being victim or perpetrator of violence, but that there are different levels of violence experience yet victim and perpetrator roles may be found together in the same clusters. Some international studies analyzed clustering looking at the victim scores of samples looking for help from society and from institutions $(8,41)$. A study in Turkey clustered women in a shelter according to whether they were exposed to different types of violence (9). These studies indicated that when the experience of violence increased, the number of clusters also increased. It was observed that the clusters obtained, as in this study, exhibited a structure of diversified types of violence at increasing levels. Therefore, findings acquired in line with the first aim of this study are consistent with the literature in pointing out that it is necessary also to investigate women's roles as perpetrators in the spiral of violence.

Findings acquired in line with the second aim of the study belonged to groups with low and moderate violence experience. These findings, jointly assessing difficulties in emotion regulation measured with DERS, signs of adult separation anxiety measured with ASA27 , and impulsiveness total scores measured with BIS11-SF, have shown that only difficulties in emotion regulation are positively related with the moderate violence cluster. As the DERS score increases, the probability of experiencing violence at a moderate rather than a low level also increases. Further analyses examining the subdimensions showed that particularly difficulties in the IMPULSE dimension were positively correlated with moderate violence. It was also seen that STRATEGIES and BSI-11-SF-MI subdimensions might be negatively correlated with moderate violence experience with borderline significance. A singlevariate analysis run additionally was able to show a positive correlation for the total ASA-27 score, when examined on its own, with moderate violence. In this study, in multivariate as well as single-variate analysis BSI-11-SF total and subdimension scores except for BSI-11-SF-MI were not correlated with moderate- or low-level violence experience. These findings partly support the second hypothesis of the study. A violence cluster significantly correlated jointly with difficulties in emotion regulation, separation anxiety, and impulsivity could not be found in the present study, while it was understood that difficulties in emotion regulation or separation anxiety each on their own could enhance moderate violence experience.

Findings indicating a correlation between the total DERS score and moderate violence experience are 
consistent with study results with women in forensic institutions who had been victims of sexual violence (42). Another study showed that the total DERS score and subdimension scores were higher for women who were perpetrators of physical violence than for women who had not perpetrated physical violence (10). However, total DERS scores and subdimension scores with the exception of AWARENESS did not differ between participants perpetrated psychological and sexual aggression and those not having perpetrated violence in these dimensions. Findings of another study carried out with female university students indicated that again especially STRATEGIES and IMPULSE dimensions were risk factors for becoming victim of violence (43). Supporting this finding, significant differences between developmentally long-term violence victims and adult violence victims only were found for IMPULSE, CLARITY, and STRATEGIES scores (13). The current literature we reviewed supports our finding that moderate rather than low-level violence experience is correlated with the IMPULSE subdimension $(13,43)$. However, the literature shows that the total DERS score or subdimension scores may not be consistently correlated with all dimensions of violence (10). In this study, based on the findings of cluster analysis we decided to use the total scores for being victim and perpetrator of violence. In the context of these findings, examining violence experiences generally rather than individual dimensions of violence, it may be assumed that only the IMPULSE subdimension could be determinant. In addition, a difference between individuals with no experience of violence and those having been victims developmentally or only in adulthood existed in behavior control, especially in the area of difficulties controlling impulses when distressed (13). Thus, for the low-level violence cluster it can be discussed that they may still experience difficulties from the perspective of dimensions of emotion regulation other than impulse control and therefore other dimensions of regulation of emotions may be correlated with low- and moderate violence experience at a similar level. Regarding our study, we need to consider that if we had reached a group that had no violence experience; results for the emotion regulation subdimensions could have been different. On the other hand, our study similarly did not reach a group with high-level violence experience. Therefore, in order to be able to see the effects in the difficulties in emotion regulation dimensions clearly and with better discrimination, we may need more heterogeneous samples with a higher number of participants from violence groups with experience at more varied levels (from zero to high). There are findings suggesting that in comparison with women who have dominantly revictimization experience, women who only suffered violence once did not show more difficulties in emotion regulation (42). Therefore, studies with samples including victims of developmental trauma, with a high proportion revictimization, or women outside the community sample might reach clearer results for the subdimensions of difficulties in emotion regulation.

Our results indicate, albeit with marginal significance, that problems specified in the STRATEGIES subdimension reduce the probability of experiencing moderate violence. As the level of significant is marginal $(\mathrm{p}<0.06)$, it may be speculative to interpret this result as a finding. However, we saw that in our study participants the mean rates of perpetrating violence were higher than the rates of being victim. Items in the STRATEGIES subdimension (e.g., "When I'm upset, I believe that there is nothing I can do to"; "When I'm upset, I believe that I'll end up feeling very depressed") suggest that they could generally evoke despair or, as a behavioral alternative, situations similar to a freeze state. While it is thought that especially perpetrating violence might serve as a type of emotion regulation tool, however dysfunctional (14), women reporting moderate violence experience in our study may have felt that those items did not represent them very much. The higher mean scores for perpetration in our study participants support this discussion.

It is believed that these relations between violence experience and difficulties in emotion regulation are not only related with violence experience of a single dimension of emotion regulation (44). Accordingly, emotion intolerance manifesting after genetic predisposition and negative experiences in the early phases of life may cause maladaptive emotion regulation tactics such as perpetrating and suffering violence $(14,45)$. This process has been found predictive not only of revictimization experiences in adulthood, but also of other psychological problems (45). We think that future studies need to assess the relation between violence or trauma victimhood and difficulties in emotion regulation with more complex designs, from a developmental perspective and with more comprehensive measuring methods.

When assessing the study results obtained by singlevariant analyses, ASA-27 total score has shown a predictive role in separating the moderate violence experience cluster from the low-intensity violence 
experience cluster. Developmental explanations of violence experience have assessed the predictive role of a continuation of childhood (anxious/disorganized) attachment into adulthood (46). At this point, our study, which also found a predictive role of anxiety experienced based on separation from significant others, can be said to be in parallel with the literature (23). Similarly, a study in pregnant women measuring adult separation anxiety symptoms using ASA-27 found that a group showing only basic characteristics of separation anxiety reported higher physical violence than women with a low level of symptoms (23). The separation anxiety symptoms assessed in the current study show similarity with the "separation anxiety disorder" as currently defined in the DSM-5 (21). According to our results, symptoms of separation anxiety measured with ASA-27 are correlated with the levels of violence regarding victimization and perpetration. It is believed that separation anxiety symptoms may be related with violence experience by creating difficulties to terminate relationships that repeat the cycle of violence. However, once difficulties in emotion regulation was added to the model in multivariate analyses, separation anxiety symptoms showed no significant correlation with low or moderate violence experience. When assessing the correlative link between the two variables, DERS and ASA-27 scores in the current study were found to be closely related at a high level $(\mathrm{r}[251]=0.53, \mathrm{p}<0.001)$. However, comparing the items on the scale that measure the two variables, their contents are not similar. This means that, though these variables may be related statistically, we assume that they reflect different experiences. While difficulties in emotion regulation reflect a general regulation problem regarding negative feelings, separation anxiety can be assumed to indicate specific concerns about separation from or loss of significant others. At this point, it can be assumed for future violence studies that entering these two variables separately in the analyses, even though they show a fairly high statistical correlation, or assessing possible mediating, moderating relations between them may be enlightening. At the same time, the fact that the symptom level of separation anxiety disorder was evaluated with a self-report instrument rather than a clinical interview may be a limitation for our assessment of the impact of separation anxiety on intimate partner violence.

The only variable used as predictor for the clusters in this study that did not show any kind of prediction was impulsiveness, measured with BIS-11-SF. However, in the literature there are findings indicating an explanatory role of impulsiveness for violence experience (47). Findings of a study examining the mediating role of impulsiveness and alexithymia in the relation between childhood emotional abuse and suffering or perpetrating violence showed that impulsiveness rather than alexithymia mediated this relation particularly in women (15). In the literature, particularly in male participants impulsiveness is an explanatory variable for perpetrating physical violence (10). The sample of this study, however, consisted of women, mainly with an experience of emotional violence; therefore, the fact that impulsiveness did not emerge as a predictive factor for the violence experience clusters might be explained with the specific characteristics of the sample. It will be a relevant contribution for future studies to address the relations examined in this paper with male participants. A study examining the influence of childhood abuse on participants' impulsivity observed that the impulsivity scores based on self-report did not match the scores obtained by laboratory tasks (48). It was pointed out that that the content of the administered instruments and the laboratory tasks may have represented different dimensions of impulsivity and thus produced this contradiction. Part of the reason why our study did not find a predictive role for impulsivity may be that we only used a self-report method to measure impulsivity and only one of the conceptualizations in the literature was represented (29). In our study, further analyses of the subdimensions of the impulsivity variable measured with BIS-11-SF showed, contrary to expectations, that a moderate rather than a low BSI-11-SF-MI score reduced the probability of experiencing moderate violence with marginal significance. If we look at the items in the BIS11-SF subdimensions, items in the Motor Impulsiveness subdimension (e.g., "I act on impulse" or "I change hobbies") by evoking the subdimension's name could have been an indication that impulsiveness was a coping experience rather than a behavioral dimension leading to violence experiences, as the subdimension name suggested. Therefore, it may be assumed that the borderline-significant reduction rather than increase of violence experience with the BSI-11-SF-MI score might originate from the item content. For further studies, it will be important to measure the impulsivity variable with different instruments and examine its interaction with coping variables, considering that the impulsivity scale items might be interpreted by the participants as some kind of coping.

Our study has certain limitations: Participants were recruited not with a non-selective method but according 
to accessibility through social networks. Furthermore, for a topic like intimate partner violence, which is mutual and difficult to separate from psychosocial context, future studies should urgently investigate possible partner effects and actor-partner interactions (49). Another limitation is the use of a self-report format to collect the data. In the cross-sectional data collection process, no empirical or semi-empirical designs, clinical interviews or observation techniques were applied. Future studies using different methods in measuring the variables and varied designs in evaluating the results of the measurements will increase the validity of the outcomes. From a different perspective, it is known that axis I and especially axis II cluster B disorders like anxiety, mood, alcohol and substance use disorders are risk factors for intimate partner violence experience (50). There are also findings showing that personality traits are individual risk factors that predict different violence groups (51). Therefore, not having used any instrument to identify and control the possible relation of psychopathological diagnoses/symptoms and personality traits with intimate partner violence can be seen as a limitation. We need to consider that assessments from the angle of psychopathology or personality traits may diversify our findings. Further studies organized with this in mind, undertaking assessment through clinical interviews, may offer a contribution to the literature. In addition, studying a topic as subjective as violence experience, controlling individuals' social desirability level may provide clearer and more reliable data (52). Therefore, future studies on the topic of our research should take into account the participants' level of social desirability.

Besides these limitations, we should also mention a number of strengths of our study. First, it is important that our study assessed perpetration and victimization of violence jointly and investigated the possible clustering in the study sample, pointing out the multidimensional nature of violence experience $(7,13)$. It was thus possible, considering the study sample structure, to define the final variable comprehensively and in detail. As far as we know, no other communitybased violence studies in Turkey investigated cluster structure. In this sense, our study can be considered as contributing to the literature. To our knowledge there is no other study investigating adult separation anxiety, which is a very new diagnosis, in the context of violence experience (33). By using such a new and diagnosis-oriented conceptualization, our study can be considered an important contribution to the literature.
Evaluating our study data obtained in a community sample of women predominantly reporting psychological violence experience, we found that the violence experiences including both victim and perpetration roles fall into 2 clusters of low and moderate level. Predictive for the distribution among the low- and medium-level violence clusters were difficulties in emotion control and separation anxiety, while impulsiveness had no predictive role. Accordingly, violence experience of women in a community sample is a complex phenomenon experienced at different levels that encompasses suffering and the perpetrating roles. The study results have drawn attention to impact of the women's affect regulation traits and their approach styles towards significant others and intimate relationships on violence experience. Accordingly, prevention and intervention programs against intimate partner violence should not be oriented solely towards male perpetrators. Violence is to be conceptualized as a process where both partners play a part, and we need to focus on the psychological and clinical determinants of violence beyond sex. Thus, our results have relevant clinical implications.

\begin{tabular}{|c|c|c|}
\hline \multicolumn{2}{|c|}{ Contribution Categories } & \multirow{2}{*}{$\begin{array}{l}\text { Author Initials } \\
\text { Y.K. }\end{array}$} \\
\hline \multirow{3}{*}{ Category 1} & Concept/Design & \\
\hline & Data acquisition & Y.K., N.T. \\
\hline & Data analysis/Interpretation & N.T. \\
\hline \multirow{2}{*}{ Category 2} & Drafting manuscript & Y.K., N.T. \\
\hline & Critical revision of manuscript & Y.K., N.T. \\
\hline Category 3 & Final approval and accountability & Y.K., N.T. \\
\hline \multirow{2}{*}{ Other } & Technical or material support & N/A \\
\hline & Supervision & N/A \\
\hline
\end{tabular}

Ethics Committee Approval: Before beginning the study, the required approval from the ethics committee of Hacettepe University was received.

Informed Consent: Written informed consent was obtained from the patients.

Peer-review: Externally peer-reviewed.

Conflict of Interest: The authors declared no conflicts of interest.

Financial Disclosure: The authors declared no financial support.

\section{REFERENCES}

1. Murphy S, Elklit A, Shevlin M. Child maltreatment typologies and intimate partner violence: findings from a Danish national study of young adults. J Interpers Violence 2017. doi: $10.1177 / 0886260517689889$.

2. Widom CS, Czaja S, Dutton MA. Child abuse and neglect and intimate partner violence victimization and perpetration: a prospective investigation. Child Abuse Negl 2014; 38:650-663. 
3. Atmaca S, Gencoz T. Exploring revictimization process among Turkish women: the role of early maladaptive schemas on the link between child abuse and partner violence. Child Abuse Negl 2016; 52:85-93.

4. Taskale N, Soygut G. Risk factors for women's intimate partner violence victimization: an examination from the perspective of the schema therapy model. J Fam Violence 2017; 32:3-12.

5. Renner LM, Whitney SD. Risk factors for unidirectional and bidirectional intimate partner violence among young adults. Child Abuse Negl 2012; 36:40-52.

6. Messman-Moore T, Ward RM, Zerubavel N, Chandley RB, Barton SN. Emotion dysregulation and drinking to cope as predictors and consequences of alcohol-involved sexual assault: examination of short-term and long-term risk. J Interpers Violence 2015; 30:601-621.

7. Ellsberg M, Pena R, Herrera A, Liljestrand J, Winkwist A. Candies in hell: women's experiences of violence in Nicaragua. Soc Sci Med 2000; 51:1595-1610.

8. Dutton MA, Kaltman S, Goodman LA, Weinfurt K, Vankos N Patterns of intimate partner violence: correlates and outcomes. Violence Vict 2005; 20:483-497.

9. Taskale N, Soygut G. Shelter-residing violence victim women: a demographic and socioeconomic examination. Turkish Psychological Articles 2016; 19:3-11. (Turkish)

10. Shorey RC, Brasfield H, Febres J, Stuart GL. An examination of the association between difficulties with emotion regulation and dating violence perpetration. J Aggress Maltreat Trauma 2011; 20:870-885.

11. Bair-Merritt MH, Crowne SS, Thompson DA, Sibinga E, Trent $\mathrm{M}$, Campbell J. Why do women use intimate partner violence? a systematic review of women's motivations. Trauma Violence Abuse 2010; 11:178-189.

12. Messman-Moore TL, Walsh KL, DiLillo D. Emotion dysregulation and risky sexual behavior in revictimization. Child Abuse Negl 2010; 34:967-976.

13. Charak R, DiLillo D, Messman-Moore TL, Gratz KL. Latent classes of lifetime sexual victimization characteristics in women in emerging adulthood: differential relations with emotion dysregulation. Psychol Violence 2017; 570-579.

14. Gratz KL, Paulson A, Jakupcak M, Tull MT. Exploring the relationship between childhood maltreatment and intimate partner abuse: gender differences in the mediating role of emotion dysregulation. Violence Vict 2009; 24:68-82.

15. Berzenski SR, Yates TM. A developmental process analysis of the contribution of childhood emotional abuse to relationship violence. J Aggress Maltreat Trauma 2010; 19:180-203.

16. Gratz KL, Roemer L. Multidimensional assessment of emotion regulation and dysregulation: Development, factor structure, and initial validation of the Difficulties in Emotion Regulation Scale. J Psychopathol Behav Assess 2004; 26:41-54.

17. Shorey RC, Brasfield H, Febres J, Stuart GL. The association between impulsivity, trait anger, and the perpetration of intimate partner and general violence among women arrested for domestic violence. J Interpers Violence 2011; 26:26812697.
18. Cunradi CB, Ames GM, Duke M. The relationship of alcohol problems to risk for unidirectional and bidirectional intimate partner violence among a sample of blue-collar couples. Violence Vict 2011;26:147-158.

19. Leone RM, Crane CA, Parrott DJ, Eckhardt CI. Problematic drinking, impulsivity, and physical IPV perpetration: a dyadic analysis. Psychol Addict Behav 2016; 30:356-366.

20. Silove D, Alonso J, Bromet E, Gruber M, Sampson N, Scott K, Andrade L, Benjet C, Caldas de Almeida JM, de Girolamo G, de Jonge P, Demyttenaere K, Fiestas F, Florescu S, Gureje O, He Y, Karam E, Lepine JP, Murphy S, Villa-Posada J, Zarkov Z, Kessler RC. Pediatric-onset and adult-onset separation anxiety disorder across countries in the World Mental Health Survey. Am J Psychiatry 2015; 172:647-656.

21. American Psychiatric Association. Diagnostic and Statistical Manual of Mental Disorders (DSM-5). Koroglu E (Translation Editor) Fifth ed., Ankara: Hekimler Yayin Birligi, 2015. (Turkish)

22. Holtzworth-Munroe A, Stuart GL, Hutchinson G. Violent versus nonviolent husbands: differences in attachment patterns, dependency, and jealousy. J Fam Psychol 1997; 11:314-331.

23. Silove DM, Tay AK, Tol WA, Tam N, Dos Reis N, de Costa Z, Soares C, Rees S. Patterns of separation anxiety symptoms amongst pregnant women in conflict-affected Timor-Leste: associations with traumatic loss, family conflict, and intimate partner violence. J Affect Disord 2016; 205:292-300.

24. Dutton DG. The Domestic Assault of Women: Psychological and Criminal Justice Perspectives. Newton MA: Allyn and Bacon, 1988, 41-42.

25. Feder L, Wilson DB. A meta-analytic review of court-mandated batterer intervention programs: can courts affect abusers' behavior? J Exp Criminol 2005; 1:239-262.

26. Straus MA, Hamby SL, McCoy S, Sugarman DB. The Revised Conflict Tactics Scales (CTS2): development and preliminary psychometric data. J Fam Issues 1996; 17:283-316.

27. Aba YA, Kulakac O. The revised conflict tactics scale (CTS2): validity and reliability study. Medical Journal of Bakirkoy 2016; 12:33-43. (Turkish)

28. Ruganci RN, Gencoz T. Psychometric properties of a Turkish version of the Difficulties in Emotion Regulation Scale. J Clin Psychol 2010; 66:442-455.

29. Patton JH, Stanford MS, Barrat ES. Factor structure of the Barratt impulsiveness scale. J Clin Psychol 1995; 51:768-774.

30. Gulec H, Tamam L, Gulec MY, Turhan M, Karakus G, Zengin M, Stanford MS. Psychometric properties of the Turkish version of the Barratt Impulsiveness Scale-11. Bulletin of Clinical Psychopharmacology 2008; 18:251-258.

31. Tamam L, Gulec H, Karatas G. Short form of Barratt Impulsiveness Scale (BIS-11-SF) Turkish adaptation study. Noro Psikiyatr Ars 2013; 50:130-134. (Turkish)

32. Manicavasagar V, Silove D, Wagner R, Drobny J. A self-report questionnaire for measuring separation anxiety in adulthood. Compr Psychiatry 2003; 44:146-153. 
33. Dirioz M, Alkin T, Yemez B, Onur E, Eminagaoglu N. The validity and reliability of Turkish version of Separation Anxiety Symptoms Inventory and Adult Separation Anxiety Questionnaire. Turk Psikiyatri Derg 2011; 23:108-116.

34. IBM SPSS Statistics for Windows. Version 21.0, New York: IBM Corporation, 2012.

35. Pockman V, Rossi FS, Holtzworth-Munroe A, Applegate AG, Beck CJ, D’Onofrio BM. Mediator's assessment of Safety Issues and Concerns (MASIC): reliability and validity of a new intimate partner violence screen. Assessment 2014; 21:529-542.

36. Taft CT, Howard J, Monson CM, Walling SM, Resick AP, Murphy CM. "Strength at Home" intervention to protect conflict and violence in military couples: pilot findings. Partner Abuse 2014; 5:41-57.

37. Field A. Discovering Statistics Using IBM SPSS Statistics. Fourth ed., Thousand Oaks CA: Sage Publications, 2013.

38. Meila M, Heckerman D. An experimental comparison of several clustering and initialization methods. The 14th Conference on Uncertainty in Artificial Intelligence, Proceedings Book, 1998, 386-395.

39. Melton HC, Belknap J. He hits, she hits: assessing gender differences and similarities in officially reported intimate partner violence. Crim Justice Behav 2003; 30:328-348.

40. Shorey RC, Cornelius TL, Bell KM. A critical review of theoretical frameworks for dating violence: comparing the dating and marital fields. Aggress Violent Behav 2008; 13:185-194.

41. Snyder DG, Fruchtman LA. Differential patterns of wife abuse: a data-based typology. J Consult Clin Psychol 1981; 49:878885.

42. Walsh K, DiLilio D, Scalora MJ. The cumulative impact of sexual revictimization on emotion regulation difficulties: an examination of female inmates. Violence Against Women 2011; 17:1103-1118
43. Walsh K, DiLillo D, Messman-Moore TL. Lifetime sexual victimization and poor risk perception: does emotion dysregulation account for the links? J Interpers Violence 2012; 27: 3054-3071.

44. Gardner FL, Moore ZE. Understanding clinical anger and violence: the anger avoidance model. Behav Modif 2008; 32:897-912.

45. Lilly MM, London MJ, Bridgett DJ. Using SEM to examine emotion regulation and revictimization in predicting PTSD symptoms among childhood abuse survivors. Psychol Trauma 2014; 6:644-651.

46. Dutton DG, White KR. Attachment insecurity and intimate partner violence. Aggress Violent Behav 2012; 17:475-481.

47. Newhill CE, Eack SM, Mulvey EP. Violent behavior in borderline personality. J Pers Disord 2009; 23:541-554.

48. Sujan AC, Humphreys KL, Ray LA, Lee SS. Differential association of child abuse with self-reported versus laboratorybased impulsivity and risk-taking in young adulthood. Child Maltreat 2014; 19:145-155.

49. Bartholomew K, Cobb RJ. Conceptualizing relationship violence as a dyadic process: In Horowitz LM, Strack S (editors). Handbook of Interpersonal Psychology: Theory, Research, Assessment and Therapeutic Interventions. New Jersey: John Wiley Sons, 2011, 233-248.

50. Spencer CM, Stith SM, Cafferky B. Risk markers for physical intimate partner violence victimization: A meta-analysis. Aggress Violent Behav 2019; 44:8-17.

51. Cascardi M, Chesin M, Kammen M. Personality correlates of intimate partner violence subtypes: A latent class analysis. Aggress Behav 2018; 44:348-361.

52. Freeman AJ, Schumacher JA, Coffey SF. Social desirability and partner agreement of men's reporting of intimate partner violence in substance abuse treatment settings. J Interpers Violence 2015; 30:565-579. 